\title{
Persistence of hepatitis B surface antibody levels after vaccination with a recombinant hepatitis $B$ vaccine: A 3-year follow-up study
}

\author{
Tetsunori Ozaki ${ }^{\S,}$, Hiroshi Mochizuki ${ }^{\S}$, Yumiko Ichikawa ${ }^{\S}$, Yoichi Fukuzawa ${ }^{\S}$, \\ Shigeru Yoshida ${ }^{\dagger}$ and Motoi Morimoto \\ ${ }^{\S}$ Department of Oral Health, Nihon University School of Dentistry, Tokyo 101-8310 \\ ${ }^{\dagger}$ Nihon University Research Center, Tokyo 101-8275 \\ and Division of Social Dentistry, Nihon University Dental Research Center, Tokyo 101-8310
}

(Received 3 March and accepted 4 September 2000)

\begin{abstract}
We conducted a 3-year follow-up study of 2,008 individuals for the persistence of antibody levels after vaccination with a recombinant hepatitis $B$ vaccine. At 1 month after vaccination had been completed $96.3 \%$ of subjects had acquired protective HB surface (HBs) antibody titers on passive hemagglutination assay (PHA) of $2^{3}$, and 3 years after completion of the vaccination $63.1 \%$ had acquired similar titers. The titer decreased below this level after 3 years in $34.5 \%$ of subjects who had initially acquired protective antibody titers. The mean acquired HBs antibody titer on PHA was $2^{5.8}$ at 1 month and $2^{3.1}$ at 3 years after completion of the vaccination. The regression line for these changes was expressed as $\log Y=1.800$ $0.24 \mathrm{X}$ by the least squares method. The antibody level was estimated to decrease to $2^{3}$ at 37 months and to seronegativity at 75 months. On the basis of the relationship between PHA antibody titers and the period of their persistence, the persistence of antibody levels after vaccination with a recombinant vaccine can be estimated from the acquired antibody titer determined 1 month after completion of the vaccination, as with plasma-derived vaccines. (J. Oral Sci. 42, 147150, 2000)
\end{abstract}

Key words: recombinant $\mathrm{HB}$ vaccine; persistence of HBs antibody levels; follow-up study.

Correspondence to Dr. Tetsunori Ozaki, Department of Oral Health, Nihon University School of Dentistry, 1-8-13 KandaSurugadai, Chiyoda-ku, Tokyo 101-8310, Japan

\section{Introduction}

It is not rare for dental care providers to come into contact with patients' blood in clinical practice. Therefore, protection against infectious diseases that can be mediated by blood, such as hepatitis B virus (HBV) infection, is a critical issue in dental practice. A useful strategy for prevention of these infections is to increase the resistance of the host, particularly by vaccination. Prevention of HBV infection by hepatitis B (HB) vaccination has been practiced for nearly 15 years. The vaccines in use were plasma-derived vaccines in the initial stage, but yeastderived recombinant $\mathrm{HB}$ vaccines are currently predominant. Data on the rate of acquisition of antibodies and their diminution after vaccination with a recombinant $\mathrm{HB}$ vaccine based on detailed surveys and studies are lacking at present, in contrast with data on plasma-derived vaccines (1).

In particular, little has been reported on decreases in acquired antibodies after vaccination $(2,3)$, and the pattern of decrease in acquired resistance after vaccination with a plasma-derived vaccine has been used as a surrogate. The key issue in vaccination in a high-risk group is the maintenance of acquired antibodies at levels high enough to prevent infection. However, currently there is no routine follow-up monitoring of antibody levels, and the pattern of decreases in acquired antibodies after vaccination with a recombinant $\mathrm{HBV}$ vaccine remains unclear.

Therefore, individuals may lose resistance to HBV after vaccination, even though they think that they are protected. In this connection, the present study was designed to determinine the optimal interval for vaccination with a 
recombinant $\mathrm{HBV}$ vaccine, the standard method of immunization, for achieving effective protection against HBV infection.

\section{Subjects and Methods}

The subjects were those who were negative for HBs antigen and antibody and had normal levels of glutamic oxaloacetic transaminase (GOT) and glutamic pyruvic transaminase (GPT) screened from among 2,158 persons who were engaged in high-risk occupations. Data from 2,008, who were examined for HBs antibody 1 month and 3 years after completion of the vaccination series were analyzed. The numbers of people vaccinated at respective stages of the study are shown in Fig. 1.

The mean age of the subjects was $34.8 \pm 9.3$ years. The vaccine used was Chinese hamster ovary-derived recombinant precipitating $\mathrm{HB}$ vaccine $(\gamma-\mathrm{HB}$ vaccine, Mitsubishi) .

According to the following method, the subjects were given two inoculations of $10 \mu \mathrm{g}$ with a 1-month interval, followed by booster immunization given 6 months later. The levels of HBs antibody in the vaccines were determined 1 month and 3 years after the third inoculation. The final titer was obtained by passive hemagglutination assay (PHA)(4). Because the study period extended to 3 years, changes in the levels of antibody from 1 month to 3 years after completion of vaccination were analyzed on the basis of the results of simultaneous assays. A regression line for these changes was calculated using SPSS 10.0J for Windows (SPSS Japan) or the least squares method (5), after transformation into a logarithm scale.

\section{Results}

The percentage of subjects with positive HBs antibody titers was $98.4 \%(n=1,476)$ at 1 month and $80.3 \%(n=$ $1,613)$ at 3 years. Table 1 shows the breakdown of vaccinations in relation to the antibody titer. The percentage of subjects who had positive PHA titers of $2^{3}$ or more was $96.3 \%(\mathrm{n}=1,933)$ at 1 month and $63.1 \%(\mathrm{n}=1,266)$ at 3 years. Changes in the HBs antibody titer over 3 years were analyzed according to high-, intermediate-, and lowresponse groups of subjects classified in terms of the PHA titer $\left(2^{6}, 2^{5} \sim 2^{4}, 2^{3}\right)$ obtained 1 month after completion of the vaccination (Table 2) In the high-response group, those who had an initial postvaccination antibody titer of $2^{7}$ or more showed a decrease in the mean antibody titer to $2^{5.6}$ at 3 years and those who had an initial postvaccination antibody titer of $2^{6}$ showed a decrease to $2^{2.8}$ at 3 years. In the intermediate-response group, subjects who had initial antibody titers of $2^{5}$ and $2^{4}$, the mean antibody titer decreased to $2^{1.8}$ and $2^{1.4}$ respectively at 3 years.

In the low-response group the antibody titer decreased from $2^{3}$ initially to $2^{1}$. The regression line for these changes was obtained by the least squares method. The time (months) until the HBs antibody titer would decrease to $2^{3}$ or to seronegativity was estimated from the obtained regression line (Table 3). The gradient of changes in the antibody titer was similar in the high- and intermediateresponse groups, whereas the low-response group showed a slightly less steep slope. On average, the changes in the antibody titer followed a regression line expressed as log $\mathrm{Y}=1.800-0.024 \mathrm{X}$. The time the antibody titer would take to reach $2^{3}$ was estimated to be 62 months, 33 months, 23 months, and 14 months after completion of the vaccination

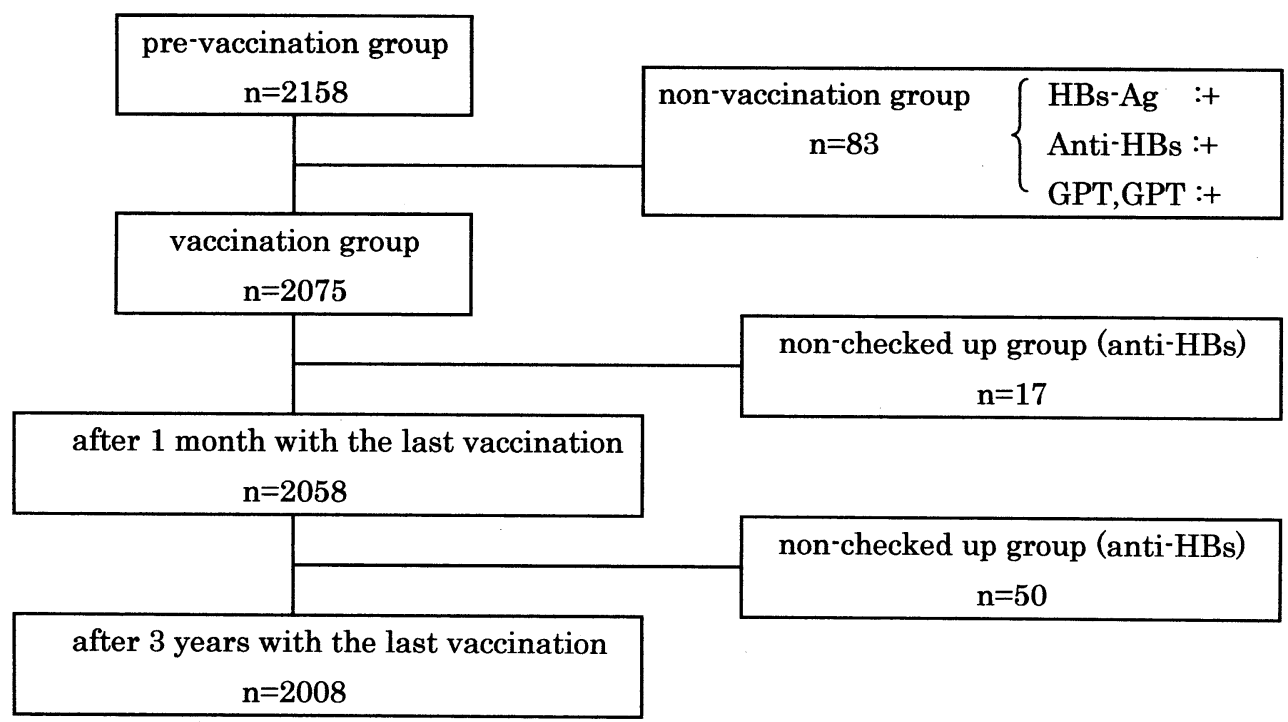

Fig. 1 The numbers of people vaccinated at respective stage of the study. 
in the subjects who had initial postvaccination antibody titers of $2^{7}$ or more, $2^{6}, 2^{5}$, and $2^{4}$, respectively. In the group as a whole, the antibody titer was estimated to decrease to $2^{3}$ at 37 months and to seronegativity at 75 months.

\section{Discussion}

Prevention of type B hepatitis by means of HB vaccination has been practiced for more than 10 years, and its great contribution to protection of infants from becoming carriers through mother-to-child transmission has been recognized (6).

However, there have been few reports on prevention of nosocomial infection by horizontal transmission. The

Table. 1 The breakdown of anti-HBs titer was acquired by reconbinant HB vaccine

\begin{tabular}{|c|c|c|c|c|c|c|c|c|}
\hline $\begin{array}{l}\text { Anti-HBs titer } \\
\left(\mathrm{PHA}=2^{\mathrm{n}}\right)\end{array}$ & & - & $2^{2}$ & $2^{3}$ & $2^{4}$ & $2^{5}$ & $2^{6}$ & $2^{7}$ \\
\hline \multirow{2}{*}{ The last vaccination } & after 1 month & 32 & 43 & 140 & 227 & 371 & 620 & 575 \\
\hline & after 3 years & 395 & 347 & 671 & 520 & 70 & 5 & 0 \\
\hline
\end{tabular}

Table. 2 Decreases of anti-HBs titers with HB vaccination for 3 years follow up

\begin{tabular}{ccc} 
& $\begin{array}{c}\text { After 1 month with } \\
\text { the last vaccination }\end{array}$ & $\begin{array}{c}\text { After 3 years with } \\
\text { the last vaccination }\end{array}$ \\
\hline High-response group & $2^{\gtrless 7}$ & $2^{5.0}$ \\
$2^{6}$ & $2^{2.8}$ \\
\hline Intermediate-response & $2^{5}$ & $2^{1.4}$ \\
group & $2^{4}$ & $2^{1.4}$ \\
\hline Low-response group & $2^{3}$ & $2^{1.0}$ \\
\hline mean & $2^{5.4}$ & 23.1 \\
\hline
\end{tabular}

available study of this kind was Rosen. et al. (7), who examined long-termed study of infections among hospital employees. According to Hadler et al.(8), the estimated protective level of HBS antibody against $\mathrm{HB}$ virus is 10 $\mathrm{mIU} / \mathrm{ml}$, which corresponds to an antibody titer of $2^{3}$ by PHA. A survey of accidental HB virus infections pointed out that, in fact, the boundary between developing and resisting the infectious disease was a PHA titer of $2^{3}$ in the host. Taking this finding into account, the percentage of subjects who acquired protective levels of antibodies with the recombinant $\mathrm{HB}$ vaccine should be regarded as 96.3 $\%$ at 1 month and $63.1 \%$ at 3 years, rather than $98.1 \%$ at 1 month and $80.3 \%$ at 3 years.

Nevertheless, these percentages are about $20 \%$ higher than the corresponding figures reported for plasmaderived vaccines. Changes in antibody levels in the subjects of our study high-, intermediate- and lowresponse groups classified in terms of the antibody titer obtained 1 month after completion of the vaccination (Fig. 2).

Although our results were expressed as straight lines because there were only two measuring points, it is apparent that the decreasing is similar for the result from plasma-devised vaccine, reported by Robert. et al. (9) and our study of vaccine. It is possible to estimate the persistence of antibody levels on the basis of the antibody titer determined 1

Table. 3 Estimated term of persistence of Anti-HBs

\begin{tabular}{|c|c|c|c|c|}
\hline $\begin{array}{l}\text { After } 1 \text { month with } \\
\text { the last vaccination }\end{array}$ & & regression line & $\begin{array}{c}\text { arrived term to } 2^{3} \text { PHA titer } \\
\text { of anti-HBs }\end{array}$ & $\begin{array}{l}\text { arrived term to seronegativiy } \\
\text { of anti-HBs }\end{array}$ \\
\hline High-response group & $\begin{array}{l}2^{\geqq 7} \\
2^{6}\end{array}$ & $\begin{array}{l}\log \mathrm{Y}=2.274-0.022 \mathrm{X} \\
\log \mathrm{Y}=1.834-0.028 \mathrm{X}\end{array}$ & $\begin{array}{l}62.54 \\
33.25\end{array}$ & $\begin{array}{r}103.54 \\
65.50\end{array}$ \\
\hline $\begin{array}{l}\text { Intermediate-response } \\
\text { group }\end{array}$ & $\begin{array}{l}2^{5} \\
2^{4}\end{array}$ & $\begin{array}{l}\log \mathrm{Y}=1.532-0.027 \mathrm{X} \\
\log \mathrm{Y}=1.226-0.022 \mathrm{X}\end{array}$ & $\begin{array}{l}23.29 \\
14.68\end{array}$ & $\begin{array}{l}56.74 \\
55.73\end{array}$ \\
\hline Low`response group & $2^{3}$ & $\log \mathrm{Y}=0.420-0.017 \mathrm{X}$ & - & 54.12 \\
\hline mean & & $\log \mathrm{Y}=1.800-0.024 \mathrm{X}$ & 37.37 & 75.00 \\
\hline
\end{tabular}




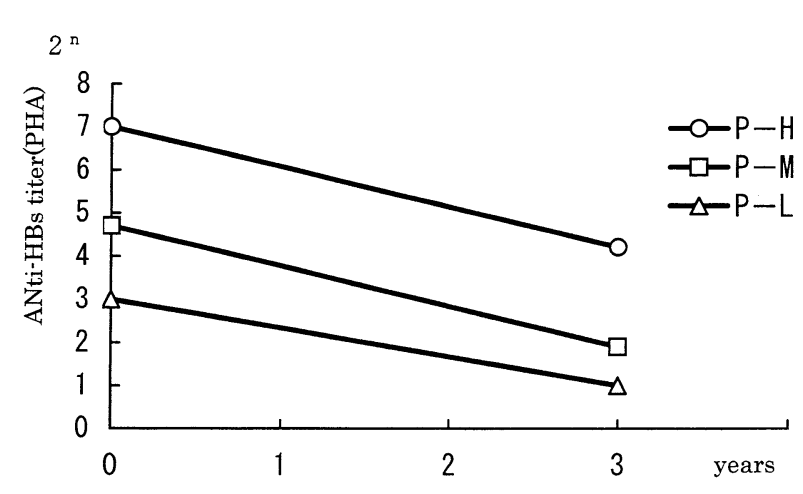

Fig. 2 Persistence of anti-HBs in reconbinant HB vaccine.

month after completion of the vaccination. According to the regression line obtained in our study, the HBs antibody titer seems to decrease to $2^{3}$ after 1-2 years in subjects with an initial PHA titer of $2^{4}$ or $2^{5}$, and after 3-5 years in those with an initial PHA titer of $2^{6}$ or higher. On average, the acquired antibody level is estimated to reach $2^{3}$ at 37 months and seronegativity at 75 months. These figures were very close to the results for a Merck recombinant vaccine reported by Iino et al.(3); they observed that HBs antibody decreased to a level of $10 \mathrm{mIU} / \mathrm{ml}$ at 37 months and to seronegativity at 77 months. Therefore, it is reasonable to conclude that the pattern of decreases in the antibody titer after vaccination with a recombinant vaccine is similar to that with a plasma-derived vaccine. The results of the present study showed that the HBs antibody titer would decrease to $1 / 2^{3}$ in 3 years, with an annual decrease of about $1 / 2$. Figure 3 is a schematic diagram of such a decrease in relation to the initially acquired antibody level.

If booster immunization is given by the time the PHA titer reaches $2^{3}$ in this schema, the protective antibody level can be maintained. For this purpose, the minimum

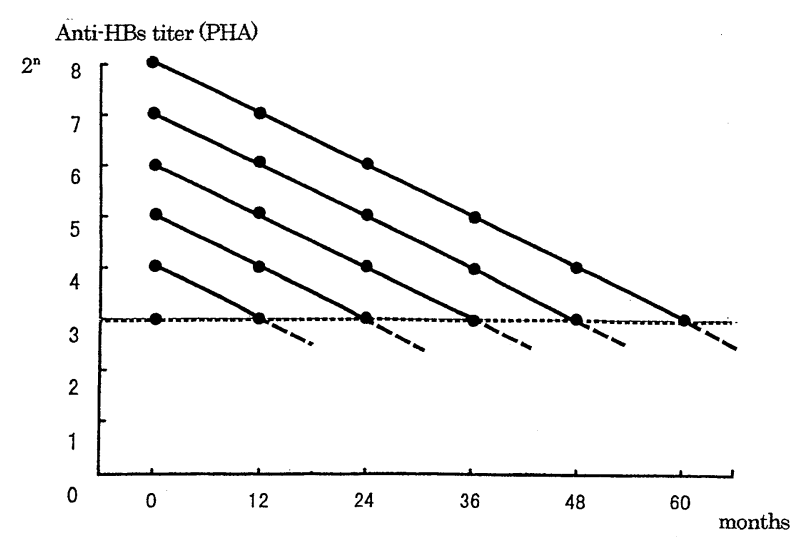

Fig. 3 A schematic diagram of such decreases in relation to initially acquired antibody level. requirement for effective prevention of $\mathrm{HB}$ infection is that each person vaccinated be aware of his or her own acquired level of antibodies by undergoing measurement of the antibody level after vaccination.

\section{References}

1. Mochizuki, H. and Morimoto, M. (1983) Incidence of hepatitis B virus infection in dental student during clinical dental training. J. Infect. Dis. 148,181

2. Jilg, W., Schmidt, M. and Deinhardt, F. (1989) Fouryear experience with a recombinant hepatitis $\mathrm{B}$ vaccine. Infection 17, 70-76

3. Iino, S., Kuroki, T., Murata, R., Tada, H., Mori, T. and Yamamoto, S. (1990) Persistence of anti-HBs after vaccination with recombinant hepatitis B vaccine and quantitative determination of anti-HBs using a standard anti-HBs sample. Yakuri To Chiryo 18, 519-529 (in Japanese)

4. Takahashi, K., Fukuda, M., Baba, K., Imai, M., Miyakawa, Y. and Mayumi, M., (1977) Determination of e antigen and antibody to e by means of passive hemagglutination method. J. Immunol. 119,1556-1559

5. Armitage, P. and Berry, G. (1994) Statistical methods in medical research. 3rd ed., Blackwell Scientific Publications, Oxford, 154-163

6. Kanai, K., Takehiro, A., Noto, H., Nishida, M., Takahashi, K., Kawashima, Y., Igarashi, Y., Matsushita, K. and Shimizu., M. (1985) Prevention of perinatal transmission of hepatitis B virus (HBV) to children of antigen-positive HBV carrier mothers by hepatitis B immune globulin and HBV vaccine. J. Infect. Dis. 151, 287-290

7. Rosen, E., Rudensky B., Paz, E., Isacsohn, M., Jerassi, Z., Gottehrer, N.P. and Yinnon, A.M. (1999) Ten-year follow-up study of hepatitis B virus infection and vaccination status in hospital employees. J. Hosp. Infect. 41,245-250

8. Hadler, S.C., Francis, D.P., Maynard, J.E., Thompson, S.E., Judson, F.N., Echenberg, D.F., Ostrow, D.G., O'Malley, P.M., Penley, K.A., Altman, N.L., Braff, E., Shipman, G.F., Coleman, P.J. and Mandel, E.J. (1986) Long-term immunogenicity and efficacy of hepatitis B vaccine in homosexual men. N. Engl. J. Med. 315, 209-214

9. Wainwright, R.B., Bulkow, L.R., Parkinson, A.J., Zanis, C. and McMahon,B.J. (1997) Protection provided by hepatitis B vaccine in a Yupik Eskimo population - results of a 10-year study. J. Infect. Dis. $175,674-677$ 